\title{
SGK1 Attenuates Oxidative Stress-Induced Renal Tubular Epithelial Cell Injury by Regulating Mitochondrial Function
}

\author{
Daofang Jiang $\mathbb{D}^{1,2}$ Chensheng Fu $\mathbb{D}^{1,2}$ Jing Xiao, ${ }^{1,2}$ Zhenxing Zhang $\mathbb{D}^{1,2}$ Jianan Zou, ${ }^{1,2}$ \\ Zhibin Ye $\mathbb{C}^{1,2}$ and Xiaoli Zhang $\mathbb{1}^{1,2}$ \\ ${ }^{1}$ Department of Nephrology, Huadong Hospital, Fudan University, Shanghai, China \\ ${ }^{2}$ Shanghai Key Laboratory of Clinical Geriatric Medicine, Shanghai, China \\ Correspondence should be addressed to Xiaoli Zhang; zhangxiaoli76@163.com
}

Received 29 March 2019; Accepted 5 August 2019; Published 18 September 2019

Academic Editor: Claudia Penna

Copyright (C) 2019 Daofang Jiang et al. This is an open access article distributed under the Creative Commons Attribution License, which permits unrestricted use, distribution, and reproduction in any medium, provided the original work is properly cited.

\begin{abstract}
Mitochondrial dysfunction has been implicated in the early stages or progression of many renal diseases. Improving mitochondrial function and homeostasis has the potential to protect renal function. Serum- and glucocorticoid-induced kinase 1 (SGK1) is known to regulate various cellular processes, including cell survival. In this study, we intend to demonstrate the effect and molecular mechanisms of SGK1 in renal tubular cells upon oxidative stress injury and to determine whether regulation of mitochondrial function is implicated in this process. HK-2 cells were exposed to $\mathrm{H}_{2} \mathrm{O}_{2}$, and cell viability and apoptosis were dynamically detected by the CCK-8 assay and annexin-V/PI staining. The concentrations of cellular reactive oxygen species (ROS) and adenosine triphosphate (ATP) and the expression of the SGK1/GSK3 $\beta /$ PGC- $1 \alpha$ signaling pathway were analyzed by flow cytometry or western blot. In addition, shRNA targeting SGK1 and SB216763 were added into the culture medium before $\mathrm{H}_{2} \mathrm{O}_{2}$ exposure to downregulate SGK1 and GSK3 $\beta$, respectively. Cell viability and mitochondrial functions, including mitochondrial membrane potential $(\Delta \psi \mathrm{m})$, Cytochrome $\mathrm{C}$ release, mtDNA copy number, and mitochondrial biogenesis, were examined. Protein levels and SGK1 activation were significantly stimulated by $\mathrm{H}_{2} \mathrm{O}_{2}$ exposure. HK-2 cells with SGK1 inhibition were much more sensitive to $\mathrm{H}_{2} \mathrm{O}_{2}$-induced oxidative stress injury than control group cells, as they exhibited increased apoptotic cell death and mitochondrial dysfunction involving the deterioration of cellular ATP production, ROS accumulation, mitochondrial membrane potential reduction, and release of Cytochrome C into the cytoplasm. Studies on SGK1 knockdown also indicated that SGK1 is required for the induction of proteins associated with mitochondrial biogenesis, including PGC- $1 \alpha$, NRF-1, and TFAM. Moreover, the deleterious effects of SGK1 suppression on cell apoptosis and mitochondrial function, including mitochondrial biogenesis, were related to the phosphorylation of GSK3 $\beta$ and partially reversed by SB216763 treatment. $\mathrm{H}_{2} \mathrm{O}_{2}$ leads to SGK1 overexpression in HK-2 cells, which protects human renal tubule cells from oxidative stress injury by improving mitochondrial function and inactivating GSK3 $\beta$.
\end{abstract}

\section{Introduction}

Oxidative stress, characterized by excessive levels of reactive oxygen species (ROS) resulting from an imbalance between the oxidative and antioxidative systems, has been widely implicated in renal pathological conditions $[1,2]$. The kidney is one of the most energy-consuming organs in the human body [3]. Owing to their active reabsorption and secretion function, renal proximal tubular cells contain the second highest mitochondrial content after only cardiomyocytes [4]. Mitochondrial dysfunction leads to decreased ATP pro- duction, increased ROS levels and, thus, loss of renal function $[5,6]$. Growing evidence show that aging is a major contributor to the increasing incidence of kidney disease. Mitochondrial dysfunction is one of the most crucial hallmarks that contribute to the process of aging. So, targeting mitochondrial function and homeostasis is a potential strategy to protect renal function and retard senescence [7].

The abundance and functional properties of mitochondria are finely modulated to meet cellular metabolic and energetic demands. Mitochondrial homeostasis requires a balance among mitochondrial biogenesis, fission and fusion, 
and mitophagy [8]. The regulation of mitochondrial homeostasis may be achieved through a set of transcription factors that transforms environmental stimuli into cellular adaptive responses. The decreased efficiency of mitochondrial biogenesis has been evidenced in multiple renal diseases $[9,10]$, and restoring mitochondrial biogenesis ameliorates the development and progression of acute kidney injury (AKI) $[11,12]$. However, the upstream regulatory signal for mitochondrial turnover in the setting of renal oxidative stress injury remains unknown [13].

Serum- and glucocorticoid-induced kinase 1 (SGK1) is a serine/threonine kinase that can be transcriptionally regulated by glucocorticoids, serum, and various cell stress stimuli, including oxidative stress, and it functions as a strong antiapoptotic kinase in these conditions [14]. Increased SGK1 expression and activity has been reported to protect endothelial cells against oxidative stress [15], while inhibition of SGK1 results in increased neurocyte stress injury $[16,17]$. Recent studies have shown that SGK1 may influence longevity and stress resistance, underscoring the clinical relevance of SGK1 in the PI3K cascade [18-20]. Our previous study demonstrated that SGK1 is dynamically overexpressed and activated upon ischemia/reperfusion injury in rat kidneys and justified that SGK1 protects renal cells from hypoxia/reoxygenation injury via promoting autophagy [21].

Thus, we wanted to further investigate whether SGK1 is implicated in the regulation of mitochondrial function in renal tubular cells under oxidative stress injury and examine the potential molecular mechanism.

\section{Materials and Methods}

2.1. Cell Culture and Treatment. Human proximal tubular epithelial cells (HK-2) were purchased from American Type Culture Collection (ATCC, Manassas, VA, USA) and cultured in Dulbecco's Modified Eagle's Medium/F12 (DMEM/F12) (Thermo Fisher Scientific, Waltham, MA, USA) supplemented with $10 \%$ heat-inactivated fetal bovine serum (FBS; Thermo Fisher Scientific), $2 \mathrm{mmol} / \mathrm{l}$ glutamine, $100 \mathrm{U} / \mathrm{ml}$ penicillin, and $100 \mathrm{mg} / \mathrm{ml}$ streptomycin at $37^{\circ} \mathrm{C}$ in a humidified incubator containing $5 \% \mathrm{CO}_{2}$.

Oxidative stress was induced by incubation of the HK-2 cells with hydrogen peroxide $\left(\mathrm{H}_{2} \mathrm{O}_{2}\right)$. Briefly, after the HK2 cells were seeded into 6- or 96-well plates, they were exposed to $\mathrm{H}_{2} \mathrm{O}_{2}$ at various concentrations for different amounts of time. HK-2 cells maintained in medium without $\mathrm{H}_{2} \mathrm{O}_{2}$ exposure were used as the normal control. For HK-2 cell transfection with shRNA, SGK1 or scramble shRNAs in the pGLV3 lentiviral vector were synthesized by GenePharma Corporation (Shanghai, China) and transfected into the HK-2 cells as described previously [21]. Briefly, the HK-2 cells were seeded in 6-well plates with serum-free DMEM and then subjected to a mixture of shRNA and Lipofectamine 3000 (Thermo Fisher Scientific) reagent. After incubation for $72 \mathrm{~h}$, the medium was changed and the cells were harvested for further experiments. For the glycogen synthase kinase $3 \beta(\mathrm{GSK} 3 \beta)$ inhibitor treatment, $\mathrm{HK}-2$ cells were treated with $10 \mu \mathrm{mol} / \mathrm{l}(\mu \mathrm{M})$ SB216763 (Selleck, Houston, TX, USA) $1 \mathrm{~h}$ prior to $\mathrm{H}_{2} \mathrm{O}_{2}$ exposure.
2.2. Cell Viability Analysis. Cell Counting Kit-8 (CCK-8; Dojindo, Kumamoto, Japan) was used to assess the viability of HK-2 cells. Briefly, $10 \mu \mathrm{l}$ of CCK- 8 reagent was added to $\mathrm{HK}-2$ cells, which were seeded in a 96-well plate in a humidified $5 \% \mathrm{CO}_{2}$ atmosphere at $37^{\circ} \mathrm{C}$ for $3 \mathrm{~h}$. The optical density (OD) was measured with a microplate reader (Thermo Fisher Scientific) at $450 \mathrm{~nm}$.

2.3. Flow Cytometry Analysis of Apoptosis. The annexin-V/PI apoptosis assay kit (Thermo Fisher Scientific) was used according to the manufacturer's recommendation to examine the apoptotic fraction of HK-2 cells after exposure to $\mathrm{H}_{2} \mathrm{O}_{2}$ for the indicated times. $\mathrm{HK}-2$ cells were washed twice with phosphate-buffered saline (PBS) and resuspended in $100 \mu \mathrm{l}$ of $1 \mathrm{x}$ binding buffer mixed with $5 \mu \mathrm{l}$ of annexin-VFITC and $5 \mu \mathrm{l}$ of a PI staining solution for $15 \mathrm{~min}$ in the dark at room temperature. After $15 \mathrm{~min}$ of incubation, another $400 \mu \mathrm{l}$ of binding buffer was added, and the cells were analyzed using a FACSCalibur flow cytometer (BD Biosciences, Franklin Lakes, NJ, USA). Ten thousand cells from the sample were scanned, and the data were analyzed using CellQuest software (BD Biosciences).

2.4. Mitochondria/Cytosol Fractionation. This assay was conducted using a Mitochondria Isolation Kit (Pierce, Rockford, IL, USA) according to the manufacturer's protocol. Cells were homogenized and the homogenates were added with $1.0 \mathrm{ml}$ of 1x Cytosol Extraction Buffer Mix and centrifuged at $750 \times \mathrm{g}$ for $10 \mathrm{~min}$ at $4^{\circ} \mathrm{C}$. Collect the supernatant carefully and discard the pellet. Then, the supernatant was centrifuged at $12,000 \times \mathrm{g}$ for $15 \mathrm{~min}$ at $4^{\circ} \mathrm{C}$; collect the supernatant and save the pellet. Next, the supernatant was further centrifuged at $100,000 \times \mathrm{g}$ for $1 \mathrm{~h}$ and the supernatant was kept as the cytosol fraction, while the pellet was resuspended with $100 \mu \mathrm{l}$ of Mitochondrial Extraction Buffer Mix and saved as a mitochondrial fraction. Then, Cytochrome C in the cytoplasm or mitochondria was detected by immunoblot analysis.

2.5. Western Blot Analysis. At the end of the culture period, HK-2 cells were collected and lysed with RIPA buffer supplemented with complete protease inhibitor cocktail tablets. Protein concentrations were determined with the BCA Protein Assay Kit (Thermo Fisher Scientific), and protein lysates (30-50 $\mu \mathrm{g}$ ) were mixed with (4x) NuPAGE LDS sample buffer, heated for $5 \mathrm{~min}$ at $99^{\circ} \mathrm{C}$, and subjected to electrophoresis on $4 \%-15 \%$ polyacrylamide gradient SDS gels. The proteins were then transferred onto PVDF membranes (Millipore, Billerica, MA, USA) and incubated with antibodies against SGK1, phosphorylated-SGK1 (p-SGK1), GSK3 $\beta$, phosphorylated-GSK $3 \beta$ (p-GSK3 $\beta$ ), cleaved caspase- 3 , and COX IV (Cell Signaling Technology, Danvers, MA, USA); peroxisome proliferator-activator $\gamma$ coactivator- $1 \alpha$ (PGC- $1 \alpha)$, Bcl-2, Bax, nuclear transcription factor-1 (NRF-1), and mitochondrial transcription factor A (TFAM) (Abcam, Cambridge, UK); and Cytochrome $\mathrm{C}$ and GAPDH (SigmaAldrich, St. Louis, MO, USA). Immunoblots were developed using an HRP-conjugated anti-rabbit or anti-mouse IgG antibody (Jackson, West Grove, PA, USA). Relative 
concentrations were assessed by densitometry analysis of digitized autographic images using ImageJ software.

2.6. Measurement of Adenosine Triphosphate (ATP) Levels. The intracellular ATP level was measured using a luciferinluciferase assay kit (Beyotime, China) according to the manufacturer's instructions. Briefly, $40 \mu \mathrm{l}$ of cell extracts or ATP standard reaction solutions, ranging from $100 \mathrm{nM}$ to $5 \mu \mathrm{M}$, was added to 96 -well luminescence assay plates. Then, $100 \mu \mathrm{l}$ of reaction buffer was added to each well. Luminescence was measured with a fluorescence microplate reader (Thermo Fisher Scientific) at a $562 \mathrm{~nm}$ absorbance. The cellular ATP content was calculated according to the ATP standard curve.

2.7. Measurement of Reactive Oxygen Species. The cellular production of ROS was measured using an ROS detection kit (Beyotime) according to the manufacturer's instructions. Briefly, HK-2 cells were incubated with $10 \mu \mathrm{M}$ DCFH-DA for $30 \mathrm{~min}$ in a dark environment at $37^{\circ} \mathrm{C}$, washed three times with warm serum-free DMEM, trypsinized, and resuspended in $1 \mathrm{ml}$ of PBS. Fluorescence was analyzed by a FACSCalibur flow cytometer (BD Biosciences).

2.8. Mitochondrial Membrane Potential Assay. Mitochondrial membrane potential $(\Delta \Psi \mathrm{m})$ was measured using a fluorescent cationic dye, 5,5',6,6 '-tetrachloro- $1,1^{\prime}, 3,3^{\prime}$-tetraethyl-imidacarbocyanine iodide (JC-1; Beyotime). The changes in $\Delta \Psi \mathrm{m}$ were determined by the levels of relative fluorescence units using a FACSCalibur flow cytometer (BD Biosciences) with a $488 \mathrm{~nm}$ excitation filter and a 525$595 \mathrm{~nm}$ emission filter.

2.9. Analysis of Mitochondrial DNA (mtDNA). Total genomic DNA was extracted using a GenElute mammalian genomic DNA kit (Sigma-Aldrich) according to the manufacturer's instructions. ND1 was used as a mtDNA marker, and the nuclear intron of $18 \mathrm{~S}$ RNA was used as a nDNA marker. The ND1 primers were designed from regions of the mtDNA that are not found in nuclear-encoded mitochondrial pseudogenes. The primers were as follows: ND1 forward $5^{\prime}$ -CCTCACTCATTTACACCAACCAC-3', reverse $5^{\prime}$-TATA ATCACTGTGCCCGCTCA-3'; $18 \mathrm{~S}$ RNA forward $5^{\prime}$-GCG GTTCTATTTTGTTGGTTTT-3', reverse $5^{\prime}$-ACCTCCGA CTTTCGTTCTTG- $3^{\prime}$. The quantification of the mtDNA product was analyzed after normalization to $18 \mathrm{~S}$ RNA.

2.10. Immunofluorescence Colocalization Analysis. HK-2 cells were incubated with $100 \mathrm{nM}$ MitoTracker Red CMXRos (Thermo Fisher Scientific) for $30 \mathrm{~min}$ at $37^{\circ} \mathrm{C}$ to label the mitochondria. To examine the Cytochrome $\mathrm{C}$ location, the cells were fixed in $4 \%$ paraformaldehyde for $15 \mathrm{~min}$ and permeabilized with $0.1 \%$ Triton X-100 for $15 \mathrm{~min}$. After blocking with $10 \%$ bovine serum albumin for $20 \mathrm{~min}$ at room temperature, the cells were incubated with a primary antibody against Cytochrome C (1:100, Sigma-Aldrich) overnight at $4^{\circ} \mathrm{C}$ and subsequently incubated with FITCconjugated secondary antibodies (1:500, Sigma-Aldrich). The colocalization of mitochondria and Cytochrome $\mathrm{C}$ was visualized by a confocal microscopy system (Leica, Wetzlar, Germany).

2.11. Statistical Analysis. All data are presented as the mean \pm standard deviation (SD). Statistical analysis was performed using Student's $t$-test or one-way ANOVA with GraphPad Prism 5.0. $P<0.05$ was recognized as statistically significant.

\section{Results}

3.1. Hydrogen Peroxide Dynamically Induces HK-2 Cell Injury and Mitochondrial Dysfunction. To mimic oxidative damage, we investigated the effect of different durations and doses of $\mathrm{H}_{2} \mathrm{O}_{2}$ exposure on the viability, apoptosis, and mitochondrial function of $\mathrm{HK}-2$ cells. As expected, a $2 \mathrm{~h}$ treatment of the $\mathrm{HK}-2$ cells with $\mathrm{H}_{2} \mathrm{O}_{2}$ resulted in a dosedependent reduction in cell survival, as evidenced by the significant decrease in the number of viable cells in comparison with that in the untreated control group, especially when the concentration of $\mathrm{H}_{2} \mathrm{O}_{2}$ was greater than $250 \mu \mathrm{M}$ (Figure 1(a)). In addition, studies on the effects of $250 \mu \mathrm{M}$ and $500 \mu \mathrm{M} \mathrm{H}_{2} \mathrm{O}_{2}$ exposure over time showed that $\mathrm{H}_{2} \mathrm{O}_{2}$ time-dependently caused HK-2 cell death (Figures 1(b) and $1(c))$. Similarly, $\mathrm{H}_{2} \mathrm{O}_{2}$ increased $\mathrm{HK}-2$ cell apoptosis in a time-dependent manner (Figure $1(\mathrm{~d})$ ). Moreover, in agreement with the CCK- 8 assay results, in which the cell viability was approximately $75 \%$ when the $\mathrm{HK}-2$ cells were treated with $250 \mu \mathrm{M} \mathrm{H}_{2} \mathrm{O}_{2}$ for $2 \mathrm{~h}$, the annexin-V/PI apoptosis examination demonstrated that the proportion of apoptotic cells under the same conditions was approximately $25 \%$.

Consistent with the above results, a significant decline in mitochondrial function was concomitantly observed in the $\mathrm{HK}-2$ cells with increasing $\mathrm{H}_{2} \mathrm{O}_{2}$ incubation time. The oxidant-induced cellular injury was associated with increased ROS accumulation and reduced cellular ATP levels compared with those in the control group when the HK-2 cells were exposed to $\mathrm{H}_{2} \mathrm{O}_{2}$ for more than $1 \mathrm{~h}$ (Figures $1(\mathrm{e})$ and $1(f))$.

3.2. $\mathrm{H}_{2} \mathrm{O}_{2}$ Time-Dependently Stimulates the SGK1-Dependent Signaling Pathway in HK-2 Cells. To further explore the mechanism of renal oxidative stress injury, we examined the SGK1/GSK3 $\beta /$ PGC- $1 \alpha$ pathway upon oxidative stress by western blot (Figure 2(a)). Treating HK-2 cells with $250 \mu \mathrm{M} \mathrm{H} \mathrm{H}_{2} \mathrm{O}_{2}$ induced robust cellular SGK1 activation (Figure 2(b)). Interestingly, this oxidative stress-induced SGK1 phosphorylation response in the HK-2 cells was fast, peaking within $1 \mathrm{~h}$ and then returning to baseline after $6 \mathrm{~h}$ (Figure 2(b)). The treatment of $\mathrm{HK}-2$ cells with $\mathrm{H}_{2} \mathrm{O}_{2}$ increased SGK1 protein levels after $30 \mathrm{~min}$ of incubation, and these levels remained elevated until $12 \mathrm{~h}$ after $\mathrm{H}_{2} \mathrm{O}_{2}$ exposure (Figure 2(c)). These results demonstrate that $\mathrm{H}_{2} \mathrm{O}_{2}$ exposure promotes both the expression and activation of the SGK1 protein in HK-2 cells. Previous studies have shown that SGK1 induced by numerous stimuli confers resistance to apoptosis through multiple signaling pathways and that GSK $3 \beta$ is an important downstream target of SGK1 [22]. Thus, we sought to explore whether GSK3 $\beta$ is involved in the $\mathrm{H}_{2} \mathrm{O}_{2}$-induced regulation of the SGK1 pathway by 


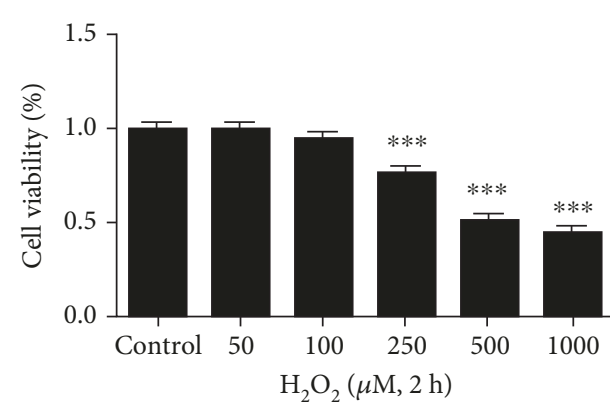

(a)

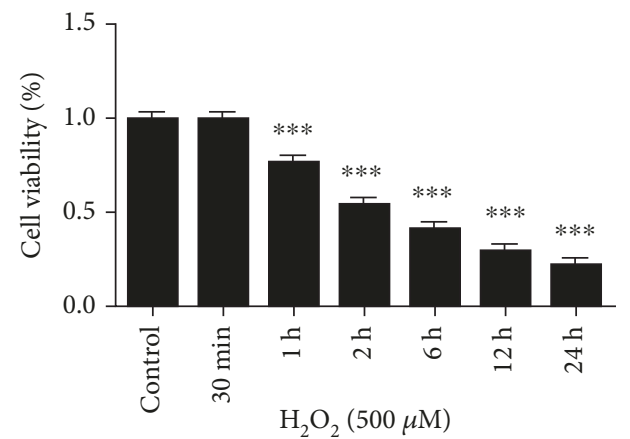

(c)

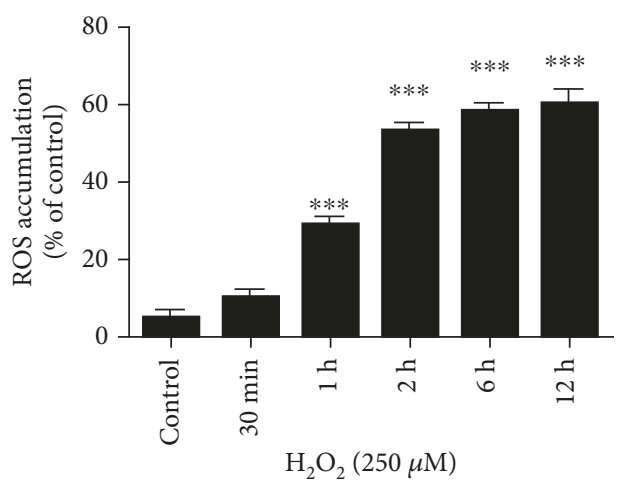

(e)

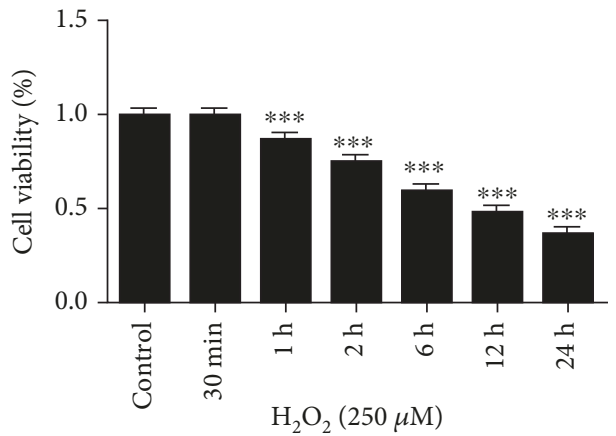

(b)

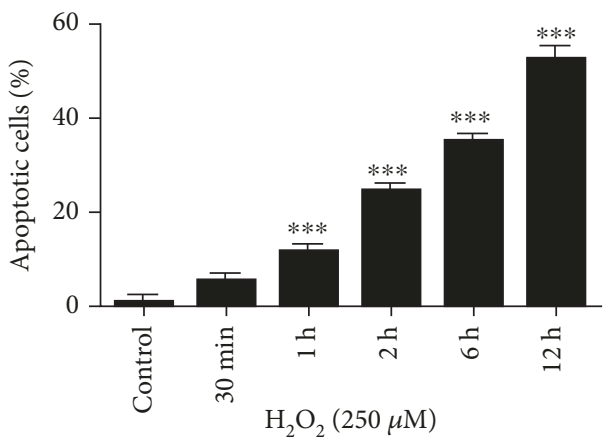

(d)

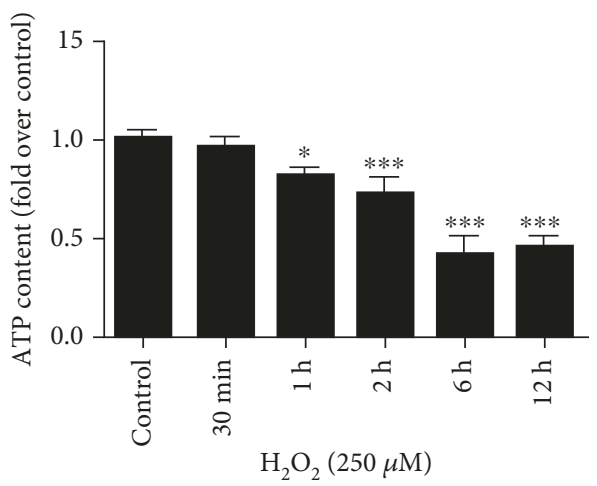

(f)

Figure 1: Oxidative stress induces HK-2 cell damage and mitochondrial dysfunction in a time- and dose-dependent manner. (a-c) Cell viability was measured in HK-2 cells treated with increasing doses of hydrogen peroxide $\left(\mathrm{H}_{2} \mathrm{O}_{2}\right)$ for different time periods. (d) Cell apoptosis was determined by flow cytometric analysis with annexin-V/PI double-staining. (e) The level of cellular ROS concentration was measured via DCFHDA fluorescence by flow cytometry. (f) A luminescence assay was used to measure the cellular ATP levels. Data are presented as the mean $\pm \mathrm{SD}(n=3) .{ }^{*} P<0.05$ and ${ }^{* * *} P<0.001$ vs. control.

measuring the phosphorylated and total levels of GSK3 $\beta$ after $\mathrm{H}_{2} \mathrm{O}_{2}$ treatment. Correlating with the increasing levels of SGK1, $\mathrm{H}_{2} \mathrm{O}_{2}$ increased the phosphorylation of GSK3 $\beta$ (Figure 2(d)). These findings indicate that upon oxidative stress, SGK1 may contribute to cell survival by phosphorylating and inactivating GSK3 $\beta$. When the $\mathrm{HK}-2$ cells were incubated with $250 \mu \mathrm{M} \mathrm{H} \mathrm{H}_{2} \mathrm{O}_{2}$, the level of PGC- $1 \alpha$ protein expression increased in a time-dependent manner (Figure 2(e)).

3.3. SGK1 Promotes Cell Viability and Inhibits the Apoptosis of HK-2 Cells Exposed to Oxidative Stress. To further study the function of the $\mathrm{H}_{2} \mathrm{O}_{2}$-induced expression and phosphor- ylation of the SGK1 protein, we mediated the knockdown of SGK1 with shRNA and pharmacologically inhibited GSK3 $\beta$ with SB21. Specifically, HK-2 cells transfected with the scramble control (null) or SGK1 shRNA (shRNA-SGK1) for $72 \mathrm{~h}$ were incubated with SB21 or DMSO for $1 \mathrm{~h}$ and then treated with $\mathrm{H}_{2} \mathrm{O}_{2}$ for $2 \mathrm{~h}$. After these treatments, cell viability, apoptosis, and mitochondrial function were determined. Transfection of the HK-2 cells with shRNA-SGK1 resulted in a significant reduction in cell viability (Figure 3(a)). The HK2 cells with SGK1 inhibition had a higher apoptotic ratio under oxidative stress (Figure 3(b)). These results indicate a critical role of SGK1 in $\mathrm{H}_{2} \mathrm{O}_{2}$-induced oxidative injury. However, SGK1 knockdown did not influence cell viability or cell 


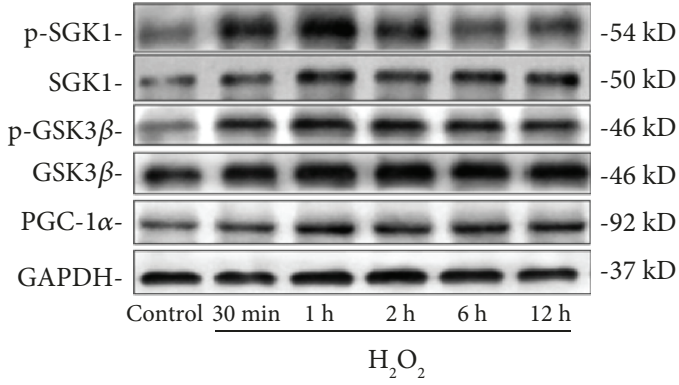

(a)

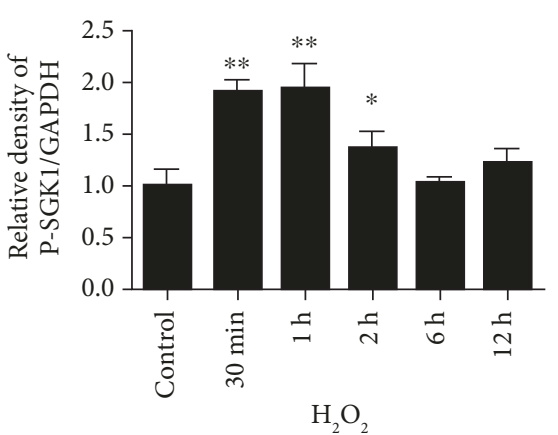

(b)

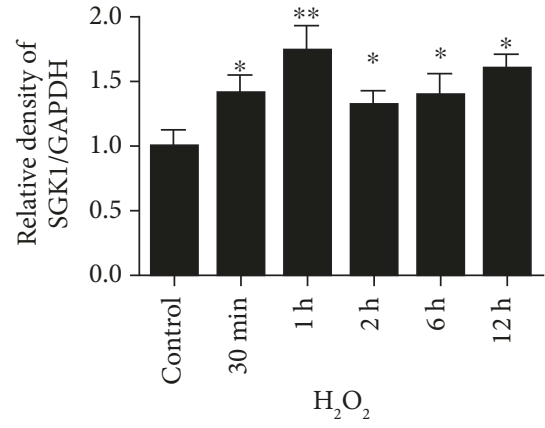

(c)

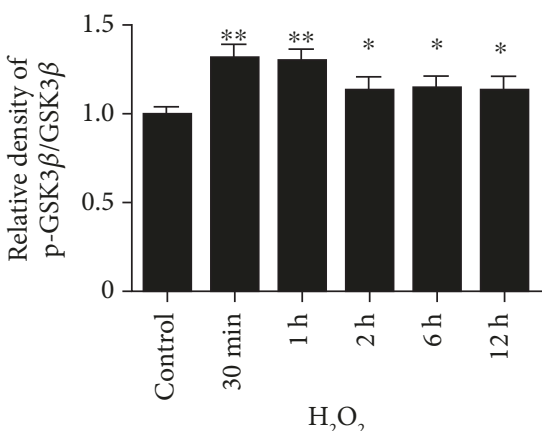

(d)

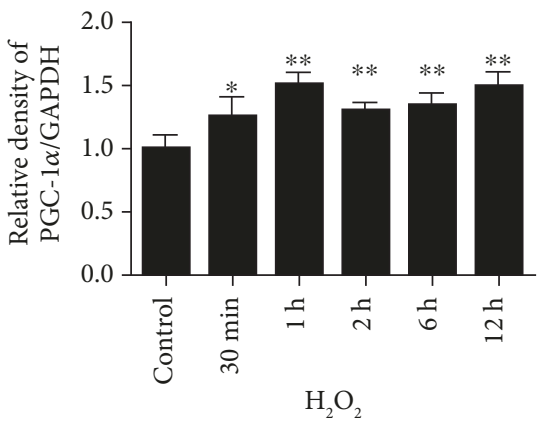

(e)

FIGURE 2: $\mathrm{H}_{2} \mathrm{O}_{2}$ time-dependently stimulates the SGK1-dependent signaling pathway in HK-2 cells. HK-2 cells were treated with $250 \mu \mathrm{M}$ $\mathrm{H}_{2} \mathrm{O}_{2}$ for different time periods. (a) Representative western blot bands are shown at the top of the corresponding graphs. (b-e) Phosphorylated SGK1 (b), total SGK1 (c), phosphorylated GSK3 $\beta$ (d), and PGC-1 $\alpha$ (e) protein levels were examined by western blot analysis. Relative protein levels were normalized to GAPDH and total GSK3 $\beta$ protein levels. Data are presented as the mean \pm SD $(n=3)$. ${ }^{*} P<0.05$ and ${ }^{* *} P<0.01$ vs. control.

apoptosis relative to the respective control cells in normal culture conditions. We also found that apoptosis-related gene expression was affected after SGK1 regulation. At the protein level, inhibiting SGK1 significantly decreased the expression of the antiapoptotic gene $\mathrm{Bcl}-2$ and distinctly increased the expression of the proapoptotic genes Bax and cleaved caspase-3 (Figures 3(d)-3(f)). Moreover, SB21 effectively ameliorated $\mathrm{H}_{2} \mathrm{O}_{2}$-induced $\mathrm{HK}-2$ cell damage (Figures 3(a) and 3(b)) and significantly attenuated the exacerbating effects of SGK1 inhibition on cell viability and apoptosis (Figures 3(a) and 3(b)). Similarly, SB21 improved the level of Bcl-2 and further reduced the levels of Bax and cleaved caspase- 3 , under oxidative stress with or without SGK1 inhibition (Figures 3(d)-3(f)).

\subsection{SGK1 Preserves Mitochondrial Function in HK-2 Cells} Exposed to Oxidative Stress. The knockdown of SGK1 further increased cellular ROS accumulation and further decreased the ATP content in HK-2 cells under oxidative stress injury (Figures 4(a) and 4(b)). The increased ROS levels and reduced ATP concentration caused by SGK1 knockdown were partly reversed by SB21 (Figures 4(a) and 4(b)). In addition, SB21 did not affect cellular ATP levels (Figure 4(b)); however, it restrained the ROS levels in HK-2 cells under $\mathrm{H}_{2} \mathrm{O}_{2}$ culture conditions (Figure $4(\mathrm{a})$ ). $\mathrm{H}_{2} \mathrm{O}_{2}$ treatment induced a reduction in $\Delta \Psi \mathrm{m}$, which was further decreased after SGK1 inhibition. SB21 obviously increased the $\mathrm{H}_{2} \mathrm{O}_{2}$ induced depolarization of $\Delta \Psi \mathrm{m}$ (Figure 5(a)). Moreover, examination of Cytochrome $\mathrm{C}$ by confocal microscopy showed that following $\mathrm{H}_{2} \mathrm{O}_{2}$ treatment, Cytochrome $\mathrm{C}$ was released into the cytoplasm, as evidenced by the decreased colocalization of Cytochrome C and MitoTracker Red staining in the mitochondria. The released quantity of Cytochrome C was increased by SGK1 knockdown but was significantly decreased in the HK-2 cells after treatment with SB21 compared with the HK-2 cells without SB21 treatment (Figure 5(b)). We then extracted the cytoplasmic and mitochondrial proteins from HK-2 cells and quantified Cytochrome $\mathrm{C}$ expression in the cytoplasm and mitochondria separately. Upon SGK1 knockdown, the level of Cytochrome $\mathrm{C}$ was increased in the cytoplasm and decreased in the mitochondria. And SB21 could partly decrease the tendency of Cytochrome $\mathrm{C}$ to release into the cytoplasm (Figures 5(c)-5(e)). These results indicate that in $\mathrm{H}_{2} \mathrm{O}_{2}$ mediated HK-2 cell injury, SGK1 may contribute to cell survival by improving mitochondrial function via the GSK3 $\beta$ dependent signaling pathway.

3.5. SGK1 Promotes Mitochondrial Biogenesis through the GSK3 $\beta$ Signaling Pathway. Quantitative analysis showed that knockdown of SGK1 dramatically decreased the mtDNA copy number compared with that in the Null $+\mathrm{H}_{2} \mathrm{O}_{2}$ group, 


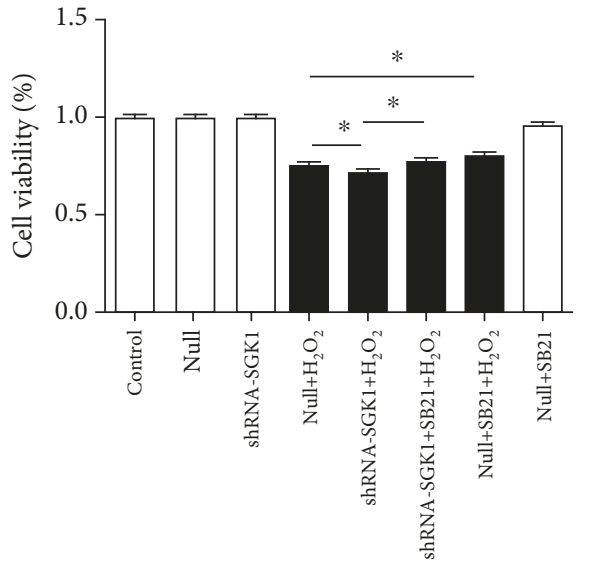

(a)

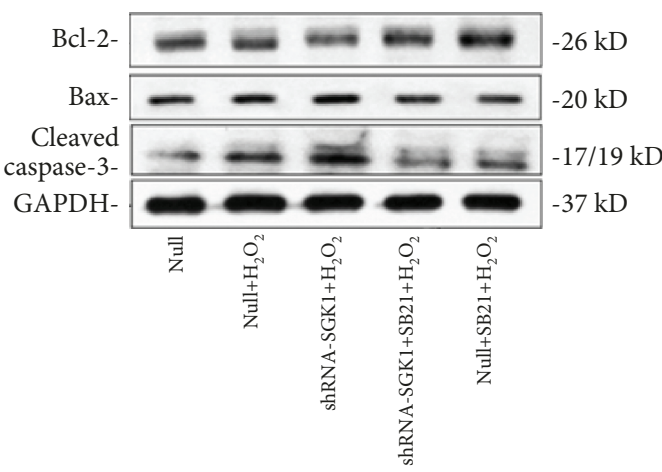

(c)

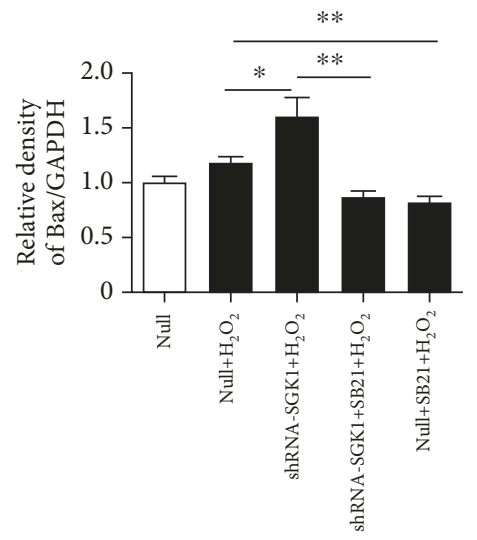

(e)

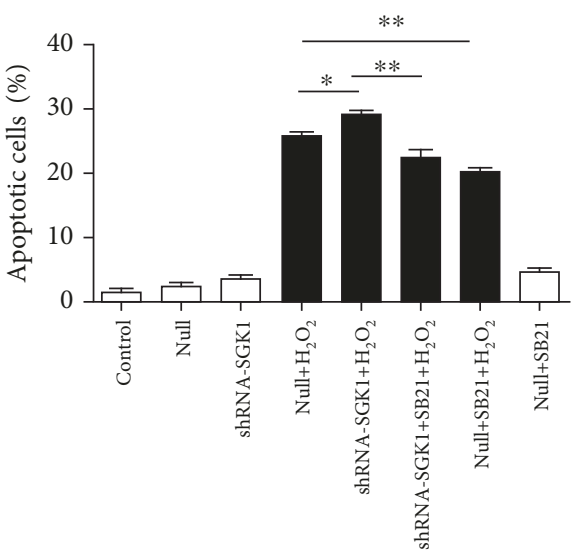

(b)

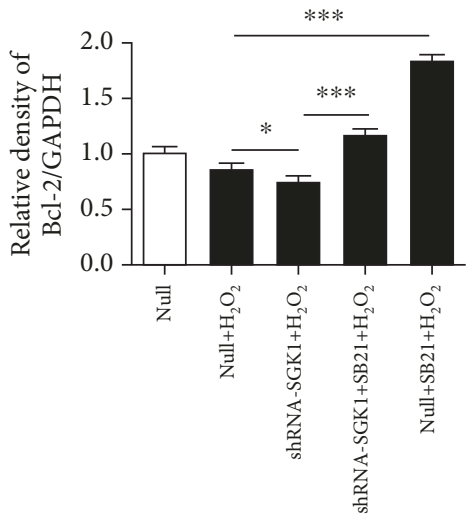

(d)

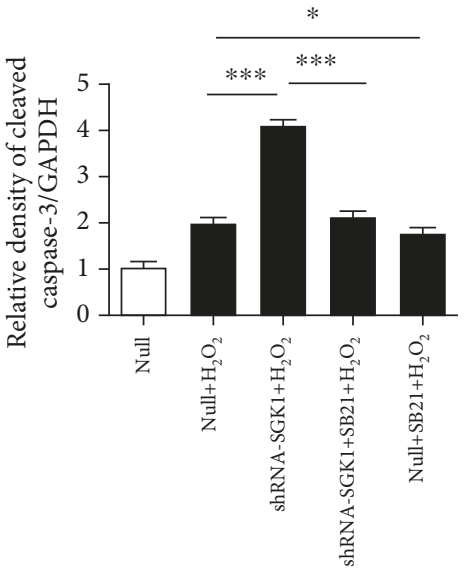

(f)

FIGURE 3: SGK1 knockdown increases $\mathrm{H}_{2} \mathrm{O}_{2}$-induced cell injury through the GSK3 $\beta$ pathway in HK-2 cells. HK-2 cells transfected with scramble control (null) or SGK1 shRNA (shRNA-SGK1) for $72 \mathrm{~h}$ were incubated with the GSK3 $\beta$ inhibitor SB216763 (SB21, $10 \mu \mathrm{M}$ ) for $1 \mathrm{~h}$ and then treated with $\mathrm{H}_{2} \mathrm{O}_{2}(250 \mu \mathrm{M})$ for $2 \mathrm{~h}$. (a) Cell viability was assessed via the CCK- 8 assay. (b) Cell apoptosis was determined by flow cytometric analysis with annexin-V/PI double-staining. (c-f) The expression levels of apoptosis-related proteins in HK-2 cells were detected by western blot analysis. Data are presented as the mean $\pm \operatorname{SD}(n=3)$. ${ }^{*} P<0.05,{ }^{* *} P<0.01$, and ${ }^{* * *} P<0.001$.

and this effect was partly reversed by SB21 exposure (Figure 6(a)). We investigated whether mitochondrial biogenesis is altered in $\mathrm{HK}-2$ cells with SGK1 regulation.

It has been reported that PGC- $1 \alpha$ and its two downstream target genes, NRF-1 and TFAM, are key regulators of mitochondrial biogenesis [23]. Therefore, we examined the levels of PGC- $1 \alpha$, NRF-1, and TFAM in SGK1knockdown HK-2 cells in the presence or absence of SB21, which indeed effectively phosphorylated and inactivated GSK3 $\beta$ (Figures $6(\mathrm{~d})-6(\mathrm{e})$ ). We found that the inhibition of SGK1 suppressed the $\mathrm{H}_{2} \mathrm{O}_{2}$-induced phosphorylation of GSK $3 \beta$ (Figures $6(\mathrm{~b})$ and $6(\mathrm{c})$ ). Knockdown of SGK1 


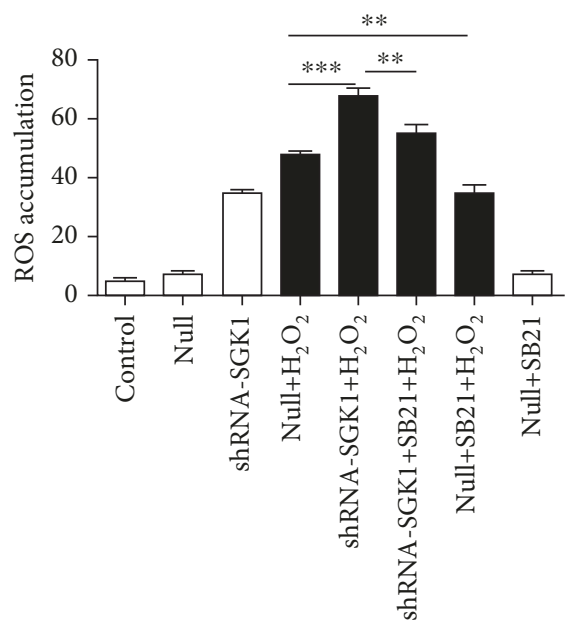

(a)

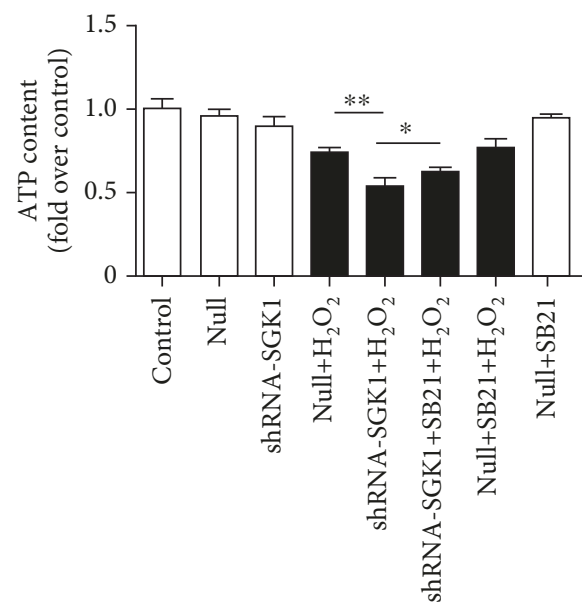

(b)

FIGURE 4: The SGK1 signaling pathway is implicated in regulating cellular ATP and ROS production upon oxidative stress. HK-2 cells transfected with scramble control (null) or SGK1 shRNA (shRNA-SGK1) for $72 \mathrm{~h}$ were incubated with $10 \mu \mathrm{M}$ SB21 for $1 \mathrm{~h}$ and then treated with or without $\mathrm{H}_{2} \mathrm{O}_{2}(250 \mu \mathrm{M})$ for $2 \mathrm{~h}$. (a) The level of cellular ROS was measured via DCFHDA fluorescence by flow cytometry. (b) A luminescence assay was used to measure the cellular ATP levels. Data are presented as the mean $\pm \mathrm{SD}(n=3) .{ }^{*} P<0.05$, ${ }^{* *} P<0.01$, and ${ }^{* * *} P<0.001$.

significantly decreased the expression of PGC- $1 \alpha$ in $\mathrm{H}_{2} \mathrm{O}_{2}$ stimulated HK-2 cells; however, the effect of SGK1 knockdown on PGC- $1 \alpha$ abundance was partially blocked by SB21. Treatment with SB21 alone obviously promoted the expression of PGC- $1 \alpha$, NRF-1, and TFAM compared with their expression in the Null $+\mathrm{H}_{2} \mathrm{O}_{2}$ group (Figures 6(f)6(i)). These findings suggest that SGK1 regulates mitochondrial biogenesis through a GSK3 $\beta$-dependent pathway.

\section{Discussion}

In this study, we demonstrated that SGK1 was upregulated and activated in HK-2 cells incubated with $\mathrm{H}_{2} \mathrm{O}_{2}$. SGK1 knockdown aggravated the cell damage and mitochondrial dysfunction caused by $\mathrm{H}_{2} \mathrm{O}_{2}$ exposure, confirming the protective role of SGK1 against oxidative injury. In addition, we showed that the inhibition of GSK $3 \beta$ mitigated HK- 2 cell injury and partly reversed the damaging effects of SGK1 knockdown upon $\mathrm{H}_{2} \mathrm{O}_{2}$-induced injury, suggesting that SGK1 might protect renal tubular cells by promoting mitochondrial function and the GSK $3 \beta$ signaling pathway.

SGK1 promotes cell survival and inhibits cell apoptosis in multiple cell lines, including renal cells [24-26]. SGK1 may represent a specific target to further develop novel therapeutic options to counteract and prevent age-related diseases. SGK1 gene expression is highly dynamic and can be regulated by diverse hormones, cytokines, and external and physiological stimuli, while SGK1 deficiency has been implicated in clinical renal pathologies [27]. SGK1 displays serine/threonine kinase activity and shares structural and functional similarities with the kinases of the Akt family [28, 29]. In this study, we demonstrated that $\mathrm{H}_{2} \mathrm{O}_{2}$-mediated SGK1 activation inhibited HK-2 cell apoptosis and promoted cell survival. In addition, SGK1 is especially more effective under pathophysiological conditions than under basic cellular conditions [30].

The mitochondrial permeability transition pore (MPTP) is located in the inner mitochondrial membrane and plays a critical role in cell death. The MPTP is closed under normal conditions and is triggered and opened when exposed to stressful stimuli, including oxidative stress [31]. Once the pore is opened, any molecule less than $1500 \mathrm{Da}$ can pass through, resulting in mitochondrial swelling, $\Delta \Psi \mathrm{m}$ depolarization, and thus ATP depletion, as well as Cytochrome C release into the cytoplasm and initiation of mitochondrial apoptosis [32]. Our data further showed that SGK1 inhibition could exaggerate mitochondrial dysfunction, confirming that SGK1 might inhibit $\mathrm{H}_{2} \mathrm{O}_{2}$-induced cytotoxicity by improving mitochondrial function.

GSK $3 \beta$ has gradually been shown to function greatly beyond glycogen metabolism, playing roles in inflammation, immunomodulation, tissue injury, repair, and regeneration [33]. Growing evidence suggests that GSK $3 \beta$ plays a detrimental role in AKI [34]. Moreover, GSK3 $\beta$ has emerged as the integration point of many significant pathways in renal cells and transfers signals downstream to regulate the opening of the MPTP [35]. A previous study verified that GSK3 $\beta$ is dynamically regulated depending on the degree of organ damage [36]. In the present experimental conditions, $\mathrm{H}_{2} \mathrm{O}_{2}$ induced the phosphorylation and inactivation of GSK3 $\beta$.

Because of its wide range of substrates, GSK $3 \beta$ plays a key and versatile role in mediating cell viability by regulating mitochondrial function $[37,38]$. The N-terminal domain of GSK3 $\beta$ has been shown to function as a mitochondrial targeting sequence, permitting the mitochondrial translocation of GSK3 $\beta$ in a kinase activity-dependent manner [39]. Dysregulation of the MPTP might be one downstream effect of GSK3 $\beta$, and phosphorylated GSK3 $\beta$ increases the MPTP opening threshold $[40,41]$. GSK $3 \beta$ activation initiates the 

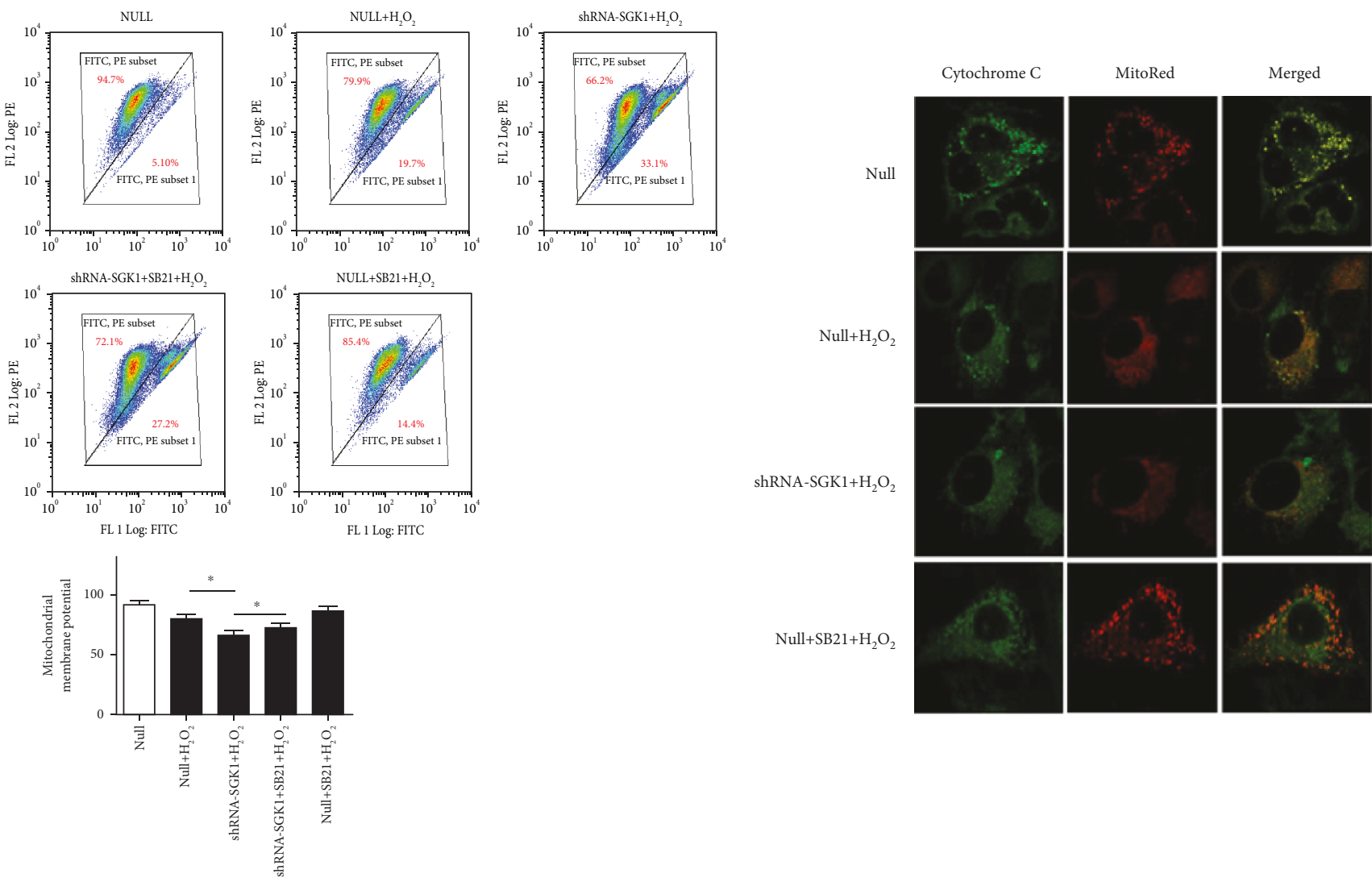

(a)

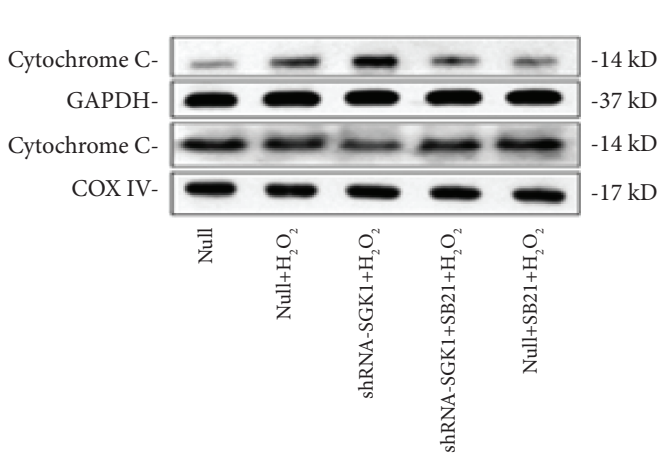

(c)

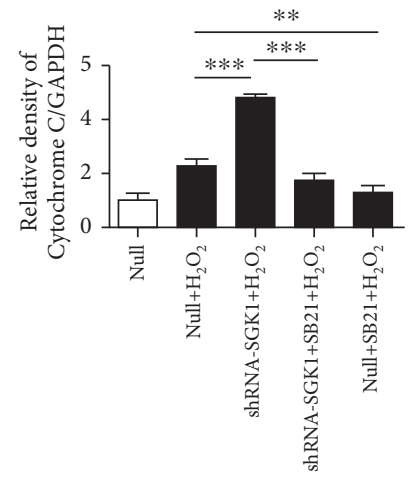

(d) (b)

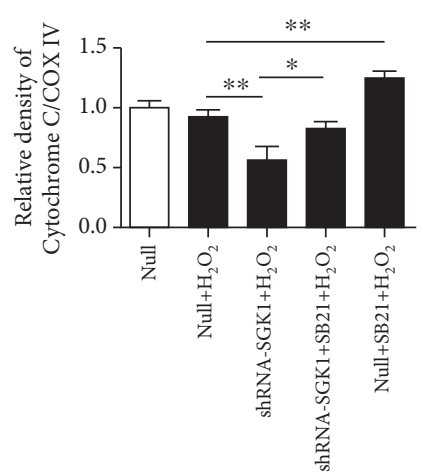

(e)

FIGURE 5: The SGK1-dependent signaling pathway modulates the mitochondrial function of HK-2 cells upon oxidative stress. HK-2 cells transfected with scramble control (null) or SGK1 shRNA (shRNA-SGK1) for $72 \mathrm{~h}$ were incubated with $10 \mu \mathrm{M}$ SB21 for $1 \mathrm{~h}$ and then treated with $\mathrm{H}_{2} \mathrm{O}_{2}(250 \mu \mathrm{M})$ for $2 \mathrm{~h}$. (a) The mitochondrial membrane potential $(\Delta \Psi \mathrm{m})$ of the HK-2 cells was measured using the lipophilic cationic dye JC-1. (b) Cytochrome C release was examined by confocal microscopy in MitoTracker Red-labeled HK-2 cells. (ce) The expression levels of Cytochrome $\mathrm{C}$ in the cytosolic and mitochondrial fractions of HK-2 cells were detected by western blot analysis. Data are presented as the mean $\pm \mathrm{SD}(n=3) .{ }^{*} P<0.05,{ }^{* *} P<0.01$, and ${ }^{* * *} P<0.001$.

caspase cascade and results in cell apoptosis. Previous studies have demonstrated that inhibition of GSK3 $\beta$ attenuates ceramide-mediated mitochondrial apoptosis by suppressing the caspase pathway [42]. Consistent with these studies, we demonstrated in this study that the GSK3 $\beta$ inhibitor SB21 might alleviate HK-2 cell apoptosis by ameliorating oxidative stress and reducing Cytochrome $\mathrm{C}$ release into the cytoplasm upon oxidative stress. Moreover, GSK3 $\beta$ phosphorylation was related to SGK1 activation, and inhibition of GSK3 $\beta$ could alleviate cell apoptosis and mitochondrial dysfunction induced by knockdown of SGK1. These results indicate that the SGK1/GSK3 $\beta$ pathway might be activated upon oxidative stress and function as an endogenous antioxidant.

Despite the transient effect on GSK $3 \beta$ during the early phase of oxidative stress, inactivation of GSK $3 \beta$ promoted the recovery of mitochondrial dysfunction. Consistent with our study, other research demonstrated that pharmacological or genetic inhibition of GSK3 $\beta$ diminished mitochondrial 


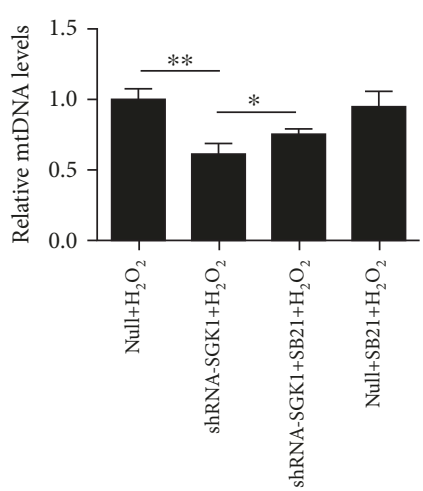

(a)

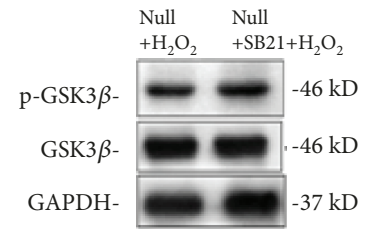

(d)

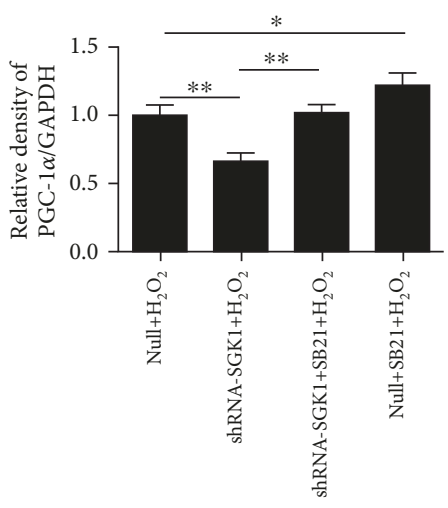

(g)

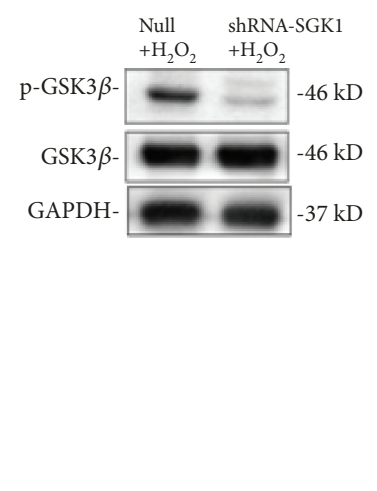

(b)

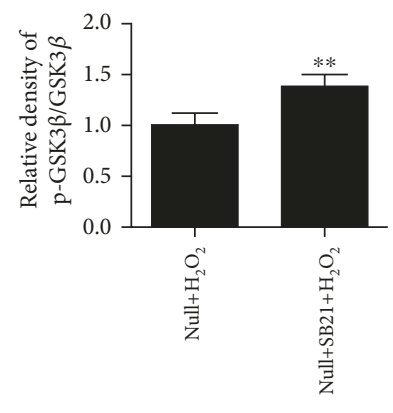

(e)

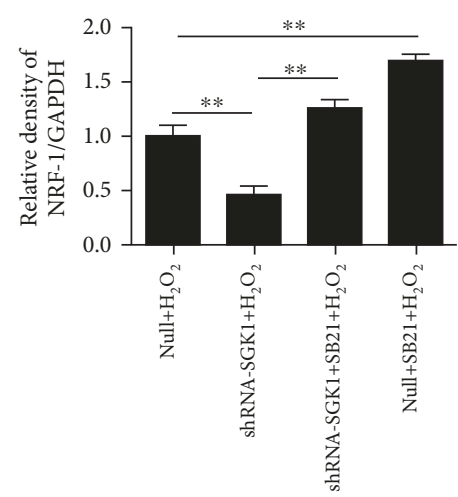

(h)

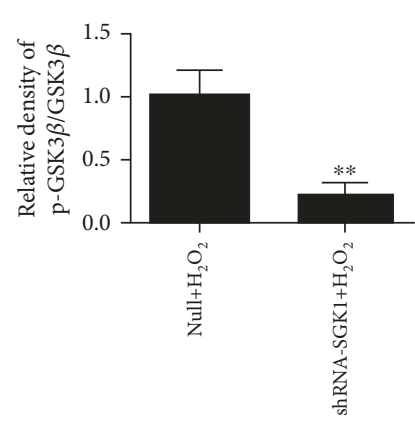

(c)

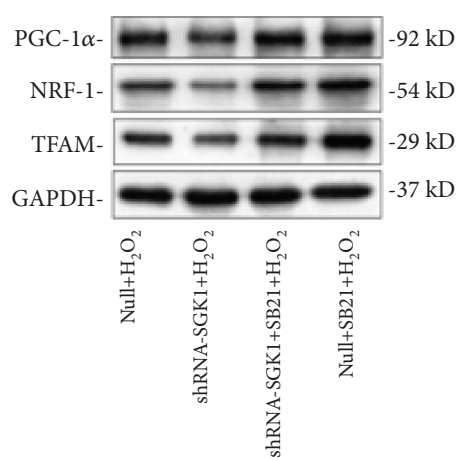

(f)

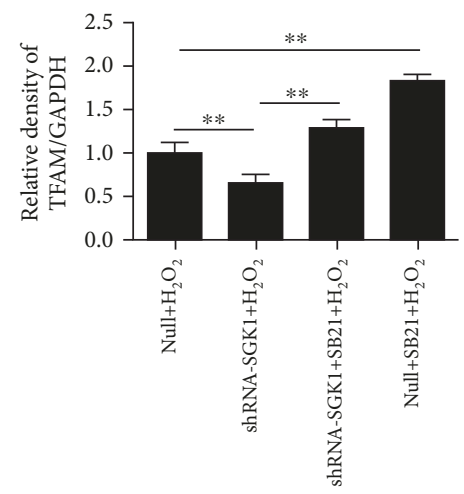

(i)

FIGURE 6: Inhibition of SGK1 downregulates mitochondrial biogenesis in a GSK3 $\beta$-dependent manner. HK-2 cells transfected with scramble control (null) or SGK1 shRNA (shRNA-SGK1) for $72 \mathrm{~h}$ were incubated with $10 \mu \mathrm{M} \mathrm{SB} 21$ for $1 \mathrm{~h}$ and then treated with $\mathrm{H}_{2} \mathrm{O}_{2}(250 \mu \mathrm{M})$ for $2 \mathrm{~h}$. (a) The mitochondrial DNA (mtDNA) copy number was detected by real-time quantitative PCR analysis. (b, c) Phosphorylated GSK3 $\beta$ protein levels after SGK1 knockdown and (d, e) SB21 treatment are shown. (f-i) Western blot analysis was performed to elucidate the effect of SGK1 knockdown and SB21 treatment on PGC-1 $\alpha$, NRF-1, and TFAM protein abundance. Relative protein levels were normalized to GAPDH and total GSK $3 \beta$ protein levels. Data are presented as the mean \pm SD $(n=3) .{ }^{*} P<0.05$ and ${ }^{* *} P<0.01$.

$\mathrm{Ca}^{2+}$ overload and subsequent cardiomyocyte death but did not modify $\Delta \Psi \mathrm{m}$ [43]. Similarly, inactivation of GSK3 $\beta$ facilitates the recovery of $\Delta \Psi \mathrm{m}$ by suppressing ROS production, leading to cytoprotection from oxidant stress-induced cell death. Interestingly, GSK $3 \beta$ inhibition improved the $\Delta \Psi \mathrm{m}$ recovery after washout of antimycin A; however, there was no change in $\Delta \Psi \mathrm{m}$ during antimycin A treatment [44]. We speculate that the effect of GSK $3 \beta$-based regulation might depend on the duration of GSK $3 \beta$ inhibition and specific experimental conditions.
Because mitochondria are involved in various cellular processes, their quantity and quality are both finely tuned. Stimulating mitochondrial biogenesis can restore mitochondrial and renal function [45]. PGC- $1 \alpha$, the master regulator of mitochondrial biogenesis, has been shown to be a GSK $3 \beta$ substrate [46]. GSK3 $\beta$ reduces PGC- $1 \alpha$ levels by phosphorylating PGC- $1 \alpha$ and subsequently stimulating PGC- $1 \alpha$ degradation by the ubiquitin-proteasomal system [47]. Simultaneously, GSK3 $\beta$ is a downstream substrate of many signaling pathways, including PI3K/Akt and insulin. 


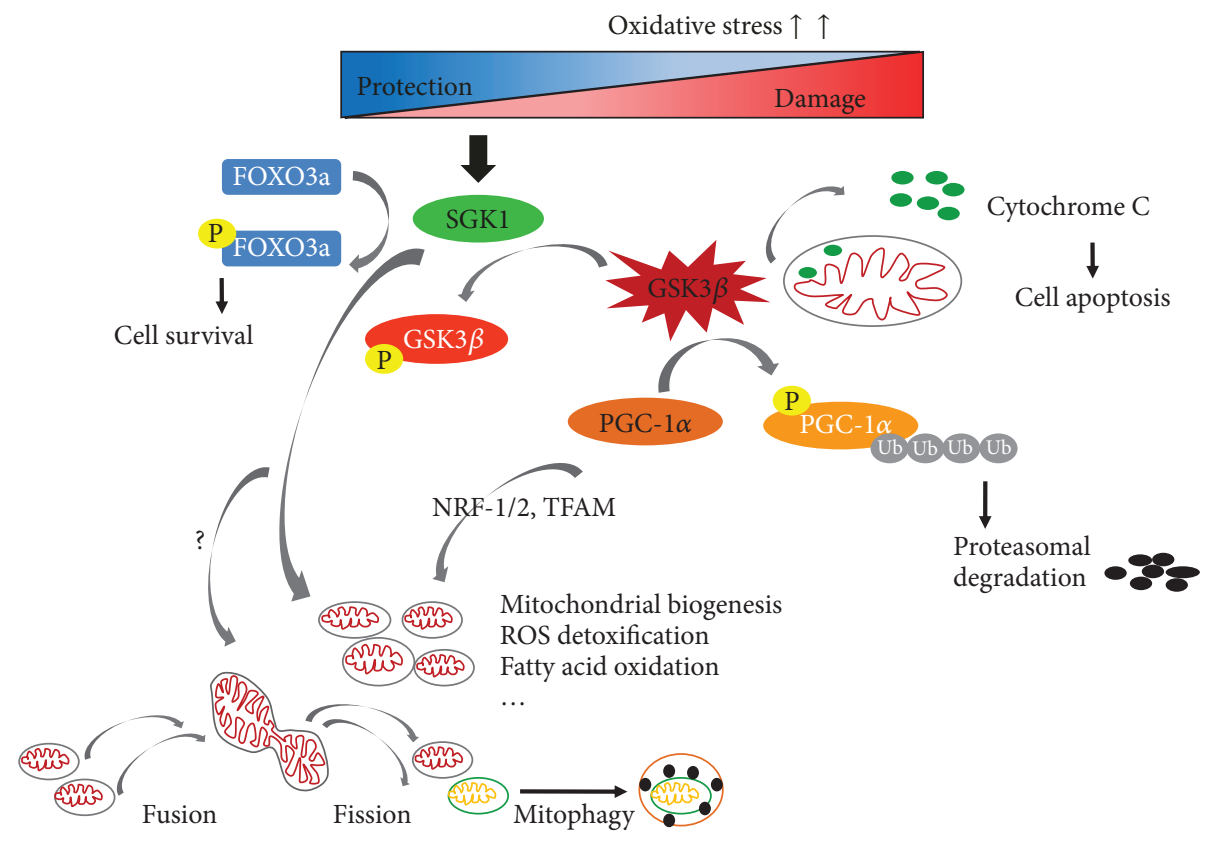

FIGURE 7: A schematic representation of the proposed mechanisms by which SGK1 regulates mitochondrial function in response to oxidative stress. Oxidative stress dynamically activates SGK1, which in turn protects cell survival through several different pathways. For example, SGK1 may phosphorylate FOXO3a and inhibit cell apoptosis [21] and SGK1 may promote mitochondrial function and mitochondrial biogenesis by phosphorylating and depressing GSK3 $\beta$ overactivation, which is widely proven to play dirty in mitochondrial homeostasis. However, whether SGK1 can regulate other processes of mitochondria turnover is worth further study. FOXO3a: forkhead box O3; Ub: ubiquitin; P: phosphorylation.

Akt was previously shown to affect cell fate by inhibiting the phosphorylation of GSK3 $\beta$ [48]. Thus, our results showed that SGK1 may exert renoprotective effects through phosphorylation of GSK $3 \beta$ and, consequently, activation of mitochondrial biogenesis. Considering the diversity of the SGK1 downstream substrates, it is explicable that the GSK3 $\beta$ inhibitor did not completely block the detrimental effects of SGK1 inhibition on cell apoptosis and mitochondrial function; i.e., other GSK $3 \beta$-independent signaling pathways may contribute to the protective effects of SGK1 [49].

A balance between mitochondrial autophagy and biogenesis is critical for mitochondrial homeostasis and turnover. With age increasing, mitochondrial integrity and biogenesis declines. Mitochondrial dysfunction is believed to be a major mechanism underlying the process of aging. Evidence suggests that with mitochondrial experimental aggravation speeding up the aging process, in contrast, its experimental amelioration delays the normal aging process [50]. So, the modulation of mitochondrial quality control can be exploited as a therapeutic target against cellular aging. A previous study showed that SGK1 delays the onset of senescence by increasing telomerase activity [20]. Our previous work has shown that SGK1 is dynamically activated during renal ischemia/reperfusion injury in rats and protects renal tubular cells against hypoxia/reoxygenation injury via promoting autophagy [21]. As a form of autophagy, mitophagy is the selective degradation of mitochondria by autophagy. So, it is reasonable to believe that SGK1 may also stimulate mitophagy while promoting autophagy. Therefore, we suggest that SGK1 is a pivotal kinase that regulates the balance between mitochon- drial biogenesis and degradation to ensure the effective function of mitochondria. In the future, we will further explore whether SGK1 can activate more specific autophagy, namely, mitophagy, as well as mitochondrial dynamics. As summarized in Figure 7, in the present study, oxidative stress could dynamically regulate SGK1 and SGK1 may act as a physiological protective factor to alleviate renal cell apoptosis, promote the quality control of mitochondria, and therefore serve as a potential intervention target against aging, which is partly dependent on the GSK3 $\beta$ signaling pathway.

\section{Data Availability}

The data used to support the findings of this study are available from the corresponding author upon request.

\section{Conflicts of Interest}

The authors declare no conflicts of interest.

\section{Acknowledgments}

This work was financially supported by the National Natural Science Foundation of China (81200494).

\section{References}

[1] L. He, Q. Wei, J. Liu et al., "AKI on CKD: heightened injury, suppressed repair, and the underlying mechanisms," Kidney International, vol. 92, no. 5, pp. 1071-1083, 2017. 
[2] A. Whaley-Connell and J. R. Sowers, "Obesity and kidney disease: from population to basic science and the search for new therapeutic targets," Kidney International, vol. 92, no. 2, pp. 313-323, 2017.

[3] Z. Wang, Z. Ying, A. Bosy-Westphal et al., "Specific metabolic rates of major organs and tissues across adulthood: evaluation by mechanistic model of resting energy expenditure," The American Journal of Clinical Nutrition, vol. 92, no. 6, pp. 1369-1377, 2010.

[4] D. J. Pagliarini, S. E. Calvo, B. Chang et al., "A mitochondrial protein compendium elucidates complex I disease biology," Cell, vol. 134, no. 1, pp. 112-123, 2008.

[5] H. H. Szeto, S. Liu, Y. Soong et al., "Mitochondria protection after acute ischemia prevents prolonged upregulation of IL- $1 \beta$ and IL-18 and arrests CKD," Journal of the American Society of Nephrology, vol. 28, no. 5, pp. 1437-1449, 2017.

[6] M. T. Coughlan, T. V. Nguyen, S. A. Penfold et al., "Mapping time-course mitochondrial adaptations in the kidney in experimental diabetes," Clinical Science, vol. 130, no. 9, pp. 711-720, 2016.

[7] H. H. Szeto, S. Liu, Y. Soong et al., "Mitochondria-targeted peptide accelerates ATP recovery and reduces ischemic kidney injury," Journal of the American Society of Nephrology, vol. 22, no. 6, pp. 1041-1052, 2011.

[8] K. Palikaras, E. Lionaki, and N. Tavernarakis, "Coordination of mitophagy and mitochondrial biogenesis during ageing in C. elegans," Nature, vol. 521, no. 7553, pp. 525-528, 2015.

[9] K. Svensson, S. Schnyder, B. Cardel, and C. Handschin, "Loss of renal tubular PGC- $1 \alpha$ exacerbates diet-induced renal steatosis and age-related urinary sodium excretion in mice," PLoS One, vol. 11, no. 7, article e0158716, 2016.

[10] M. Tran, D. Tam, A. Bardia et al., "PGC- $1 \alpha$ promotes recovery after acute kidney injury during systemic inflammation in mice," The Journal of Clinical Investigation, vol. 121, no. 10, pp. 4003-4014, 2011.

[11] M. T. Tran, Z. K. Zsengeller, A. H. Berg et al., "PGC1 $\alpha$ drives NAD biosynthesis linking oxidative metabolism to renal protection," Nature, vol. 531, no. 7595, pp. 528-532, 2016.

[12] S. R. Jesinkey, J. A. Funk, L. J. Stallons et al., "Formoterol restores mitochondrial and renal function after ischemiareperfusion injury," Journal of the American Society of Nephrology, vol. 25, no. 6, pp. 1157-1162, 2014.

[13] P. Bhargava and R. G. Schnellmann, "Mitochondrial energetics in the kidney," Nature Reviews Nephrology, vol. 13, no. 10, pp. 629-646, 2017.

[14] F. Lang, C. Böhmer, M. Palmada, G. Seebohm, N. StrutzSeebohm, and V. Vallon, "(Patho)physiological significance of the serum- and glucocorticoid-inducible kinase isoforms," Physiological Reviews, vol. 86, no. 4, pp. 1151-1178, 2006.

[15] F. Ferrelli, D. Pastore, B. Capuani et al., "Serum glucocorticoid inducible kinase (SGK)-1 protects endothelial cells against oxidative stress and apoptosis induced by hyperglycaemia," Acta Diabetologica, vol. 52, no. 1, pp. 55-64, 2015.

[16] C. Talarico, V. Dattilo, L. D’Antona et al., “SI113, a SGK1 inhibitor, potentiates the effects of radiotherapy, modulates the response to oxidative stress and induces cytotoxic autophagy in human glioblastoma multiforme cells," Oncotarget, vol. 7, no. 13, pp. 15868-15884, 2016.

[17] P. Licznerski, V. Duric, M. Banasr et al., "Decreased SGK1 expression and function contributes to behavioral deficits induced by traumatic stress," PLoS Biology, vol. 13, no. 10, article e1002282, 2015.

[18] A. Orlacchio, M. Ranieri, M. Brave et al., "SGK1 is a critical component of an AKT-independent pathway essential for PI3K-mediated tumor development and maintenance," Cancer Research, vol. 77, no. 24, pp. 6914-6926, 2017.

[19] A. T. Y. Chen, C. Guo, K. J. Dumas, K. Ashrafi, and P. J. Hu, "Effects of Caenorhabditis elegans sgk-1 mutations on lifespan, stress resistance, and DAF-16/FoxO regulation," Aging Cell, vol. 12, no. 5, pp. 932-940, 2013.

[20] D. Lauro, D. Pastore, B. Capuani et al., "Role of serum and glucocorticoid-inducible kinase (SGK)-1 in senescence: a novel molecular target against age-related diseases," Current Medicinal Chemistry, vol. 22, no. 33, pp. 3765-3788, 2015.

[21] Y. Xie, D. Jiang, J. Xiao et al., "Ischemic preconditioning attenuates ischemia/reperfusion-induced kidney injury by activating autophagy via the SGK1 signaling pathway," Cell Death \& Disease, vol. 9, no. 3, p. 338, 2018.

[22] J. Cheng, L. D. Truong, X. Wu, D. Kuhl, F. Lang, and J. du, "Serum- and glucocorticoid-regulated kinase 1 is upregulated following unilateral ureteral obstruction causing epithelialmesenchymal transition," Kidney International, vol. 78, no. 7, pp. 668-678, 2010.

[23] A. Prola, K. Monceaux, Z. Nichtova et al., "ER stress induces cardiac dysfunction through architectural modifications and alteration of mitochondrial function in cardiomyocytes," Cardiovascular Research, vol. 10, no. 2, p. 189, 2018.

[24] W. Wu, S. Chaudhuri, D. R. Brickley, D. Pang, T. Karrison, and S. D. Conzen, "Microarray analysis reveals glucocorticoidregulated survival genes that are associated with inhibition of apoptosis in breast epithelial cells," Cancer Research, vol. 64, no. 5, pp. 1757-1764, 2004.

[25] J. Li, Q. Zhou, T. Yang et al., "SGK1 inhibits PM2.5-induced apoptosis and oxidative stress in human lung alveolar epithelial A549 cells," Biochemical and Biophysical Research Communications, vol. 496, no. 4, pp. 1291-1295, 2018.

[26] C. Wu, Z. Chen, S. Xiao et al., "SGK1 governs the reciprocal development of Th17 and regulatory T cells," Cell Reports, vol. 22, no. 3, pp. 653-665, 2018.

[27] F. Lang, F. Artunc, and V. Vallon, "The physiological impact of the serum and glucocorticoid-inducible kinase SGK1," Current Opinion in Nephrology and Hypertension, vol. 18, no. 5, pp. 439-448, 2009.

[28] C. E. Gleason, J. A. Oses-Prieto, K. H. Li et al., "Phosphorylation at distinct subcellular locations underlies specificity in mTORC2-mediated activation of SGK1 and Akt," Journal of Cell Science, vol. 132, no. 7, p. jcs224931, 2019.

[29] I. Alesutan, J. Voelkl, M. Feger et al., "Involvement of vascular aldosterone synthase in phosphate-induced osteogenic transformation of vascular smooth muscle cells," Scientific Reports, vol. 7, no. 1, article 2059, 2017.

[30] P. Wulff, V. Vallon, D. Y. Huang et al., "Impaired renal $\mathrm{Na}^{+}$ retention in the sgk1-knockout mouse," The Journal of Clinical Investigation, vol. 110, no. 9, pp. 1263-1268, 2002.

[31] A. P. Halestrap, "What is the mitochondrial permeability transition pore?," Journal of Molecular and Cellular Cardiology, vol. 46, no. 6, pp. 821-831, 2009.

[32] K. Li, Y. Li, J. M. Shelton et al., "Cytochrome c deficiency causes embryonic lethality and attenuates stress-induced apoptosis," Cell, vol. 101, no. 4, pp. 389-399, 2000. 
[33] G. V. Rayasam, V. K. Tulasi, R. Sodhi, J. A. Davis, and A. Ray, "Glycogen synthase kinase 3: more than a namesake," British Journal of Pharmacology, vol. 156, no. 6, pp. 885-898, 2009.

[34] H. Bao, Y. Ge, S. Zhuang, L. D. Dworkin, Z. Liu, and R. Gong, "Inhibition of glycogen synthase kinase- $3 \beta$ prevents NSAIDinduced acute kidney injury," Kidney International, vol. 81, no. 7, pp. 662-673, 2012.

[35] Z. Liu and R. Gong, "Remote ischemic preconditioning for kidney protection: GSK $3 \beta$-centric insights into the mechanism of action," American Journal of Kidney Diseases, vol. 66, no. 5, pp. 846-856, 2015.

[36] H. Bao, Y. Ge, Z. Wang et al., "Delayed administration of a single dose of lithium promotes recovery from AKI," Journal of the American Society of Nephrology, vol. 25, no. 3, pp. 488500, 2014.

[37] K. Yang, Z. Chen, J. Gao et al., "The key roles of GSK-3 $\beta$ in regulating mitochondrial activity," Cellular Physiology and Biochemistry, vol. 44, no. 4, pp. 1445-1459, 2017.

[38] P. Cohen and S. Frame, "The renaissance of GSK3," Nature Reviews Molecular Cell Biology, vol. 2, no. 10, pp. 769-776, 2001.

[39] M. Tanno, A. Kuno, S. Ishikawa et al., "Translocation of glycogen synthase kinase- $3 \beta$ (GSK-3 $\beta$ ), a trigger of permeability transition, is kinase activity-dependent and mediated by interaction with voltage-dependent anion channel 2 (VDAC2)," The Journal of Biological Chemistry, vol. 289, no. 42, pp. 29285-29296, 2014.

[40] M. Juhaszova, D. B. Zorov, S. H. Kim et al., "Glycogen synthase kinase-3beta mediates convergence of protection signaling to inhibit the mitochondrial permeability transition pore," The Journal of Clinical Investigation, vol. 113, no. 11, pp. 15351549, 2004.

[41] J. Zhu, M. J. Rebecchi, P. S. A. Glass, P. R. Brink, and L. Liu, "Interactions of GSK-3 $\beta$ with mitochondrial permeability transition pore modulators during preconditioning: ageassociated differences," The Journals of Gerontology Series A: Biological Sciences and Medical Sciences, vol. 68, no. 4, pp. 395-403, 2013.

[42] C. F. Lin, C. C. Tsai, W. C. Huang et al., "Glycogen synthase kinase- $3 \beta$ and caspase- 2 mediate ceramide- and etoposideinduced apoptosis by regulating the lysosomal-mitochondrial axis," PLoS One, vol. 11, no. 1, article e0145460, 2016.

[43] L. Gomez, P. A. Thiebaut, M. Paillard et al., "The SR/ER-mitochondria calcium crosstalk is regulated by GSK3 $\beta$ during reperfusion injury," Cell Death and Differentiation, vol. 22, no. 11, article 1890, 2015.

[44] D. Sunaga, M. Tanno, A. Kuno et al., "Accelerated recovery of mitochondrial membrane potential by GSK-3 $\beta$ inactivation affords cardiomyocytes protection from oxidant-induced necrosis," PLoS One, vol. 9, no. 11, article e112529, 2014.

[45] E. Arif, A. K. Solanki, P. Srivastava et al., "Mitochondrial biogenesis induced by the $\beta 2$-adrenergic receptor agonist formoterol accelerates podocyte recovery from glomerular injury," Kidney International, vol. 96, no. 3, pp. 656-673, 2019.

[46] B. L. Olson, M. B. Hock, S. Ekholm-Reed et al., "SCF ${ }^{\mathrm{Cdc} 4}$ acts antagonistically to the PGC- $1 \alpha$ transcriptional coactivator by targeting it for ubiquitin-mediated proteolysis," Genes \& Development, vol. 22, no. 2, pp. 252-264, 2008.

[47] R. Xu, Q. Hu, Q. Ma, C. Liu, and G. Wang, "The protease Omi regulates mitochondrial biogenesis through the GSK3 $\beta / \mathrm{PGC}$ -
$1 \alpha$ pathway," Cell Death \& Disease, vol. 5, no. 8, article e1373, 2014.

[48] Y. Zhang, Z. Xia, K. H. La Cour, and J. Ren, “Activation of Akt rescues endoplasmic reticulum stress-impaired murine cardiac contractile function via glycogen synthase kinase- $3 \beta$-mediated suppression of mitochondrial permeation pore opening," Antioxidants \& Redox Signaling, vol. 15, no. 9, pp. 24072424, 2011.

[49] F. Lang and J. Voelkl, "Therapeutic potential of serum and glucocorticoid inducible kinase inhibition," Expert Opinion on Investigational Drugs, vol. 22, no. 6, pp. 701-714, 2013.

[50] C. López-Otín, M. A. Blasco, L. Partridge, M. Serrano, and G. Kroemer, "The hallmarks of aging," Cell, vol. 153, no. 6, pp. 1194-1217, 2013. 


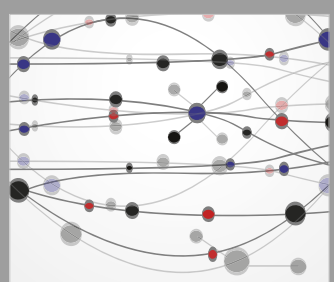

The Scientific World Journal
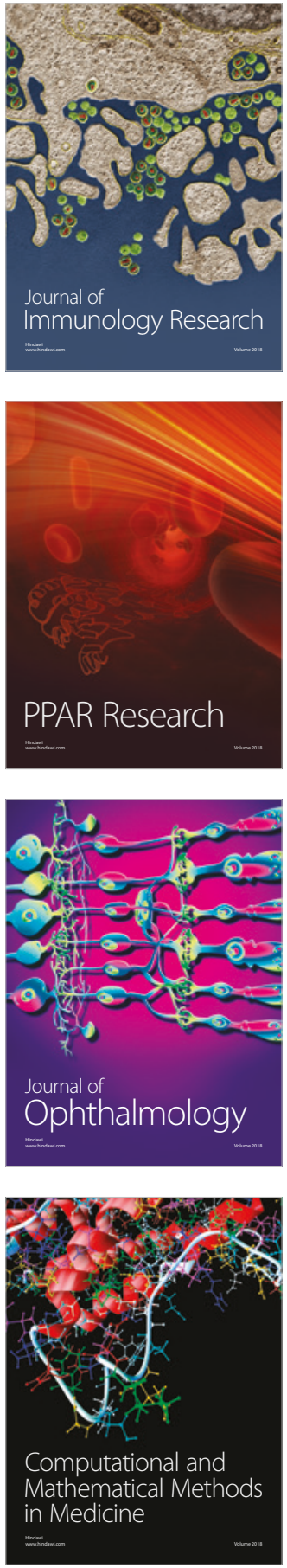

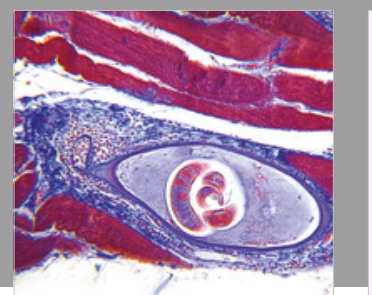

Gastroenterology Research and Practice

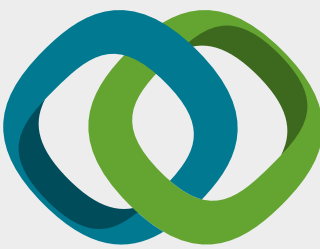

\section{Hindawi}

Submit your manuscripts at

www.hindawi.com
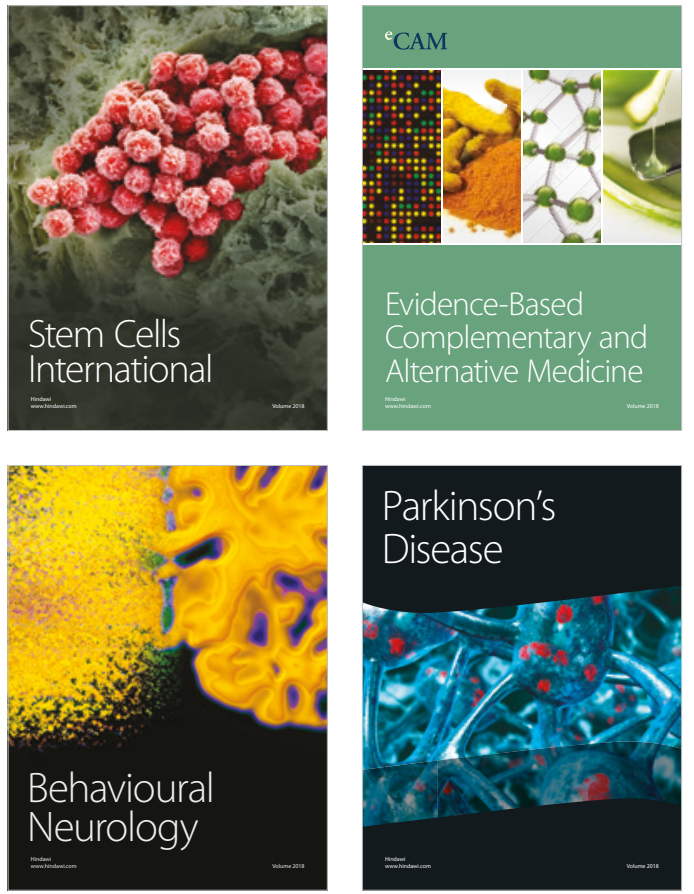

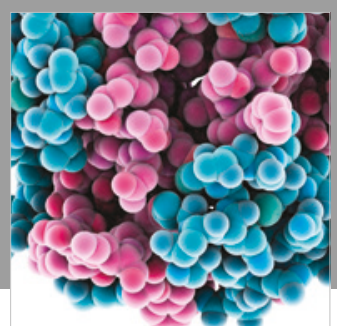

ournal of

Diabetes Research

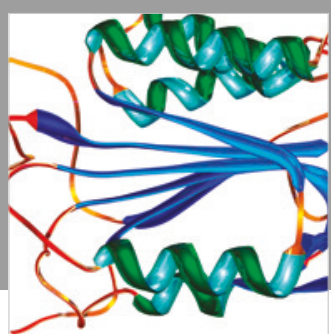

Disease Markers
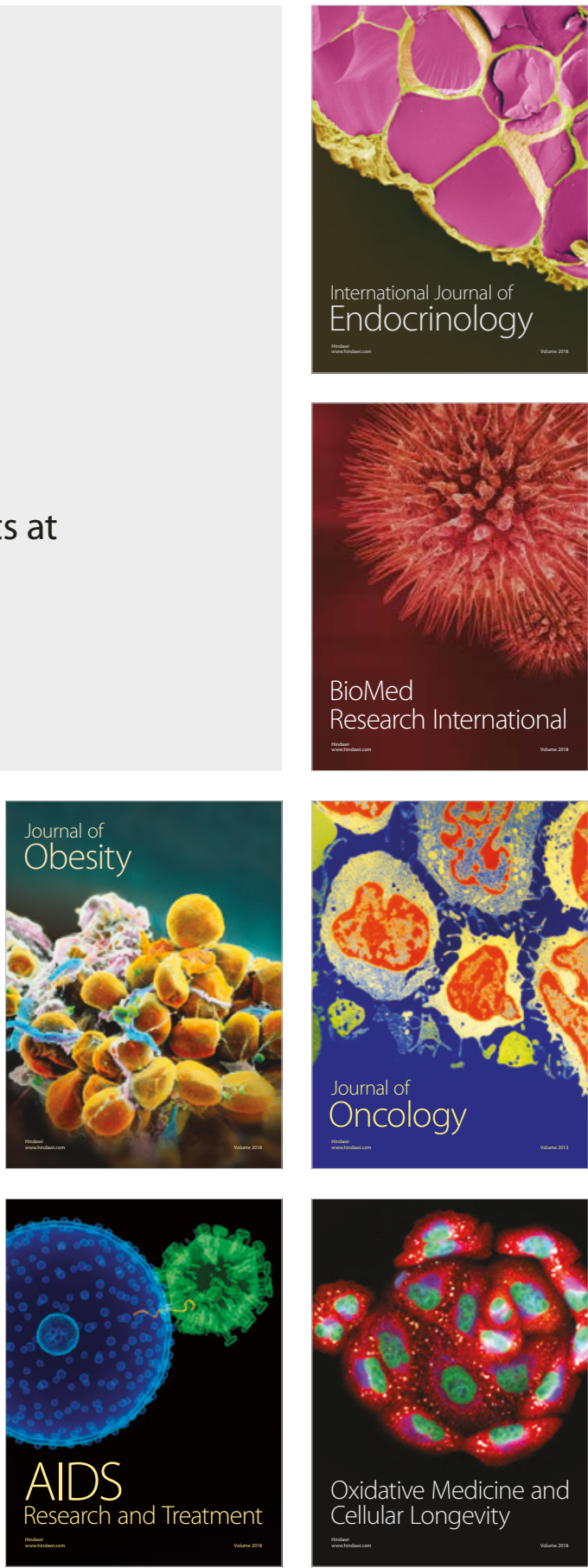